\title{
Kolektif Öğretmen Yeterliğinin Öğretmen İş̧ Doyumundaki Rolü Üzerine Yapısal Eşitlik Modellemesi
}

\author{
DOI: 10.26466/opus.496333 \\ * \\ $\underline{\text { Selçuk Demir }}^{*}$ \\ * Dr, Milli Eğitim Bakanlığı, Hatay/ Türkiye \\ E-Posta: selcukdemirs3@gmail.com \\ ORCID:0000-0003-2904-6443
}

\section{Öz}

Bu çalışmada kolektif öğretmen yeterliği ile öğretmen iş doyumu arasındaki ilişkinin tespit edilmesi amaçlanmıştır. Araştırmada ilişkisel tarama modeli kullanılmıştır. Araştırmanın örneklemi, Hatay'ın Samandă̆ ilçesinde bulunan okullarda 2018-2019 eğitim-öğretim yılında görev yapmakta olan öğretmenler arasından küme örnekleme yöntemiyle yansı olarak seçilmiş 26 okulda çalışan 235 öğretmen oluşturmaktadır. Araştırma verilerinin toplanmasında "Öğretmen Kolektif Yeterlik Ölçeği" ve "İş Doyumu Ölçeği" kullanılmıştır. Öğretmenlerin kolektif yeterliklerine, kollektif yeterliğin öğretim stratejileri ve öğrenci disiplinine ve iş doyumuna ilişkin algıları kısmen yüksek düzeydedir. Yapısal eşitlik modellemesi sonuçlarına göre; kolektiföğretmen yeterliği, iş doyumunu pozitif yönde etkilemektedir. Ayrıca kolektiföğretmen yeterliğinin öğretim stratejileri ve öğrenci disiplini alt boyutları, iş doyumunu pozitif olarak etkilemektedir. Araştırma sonuçlarına bağlı kalınarak, öğretmenlerin iş memnuniyetlerinin arttırlmasında kolektif yeterlik algılarının pekiştirilmesi gerekmektedir. Kolektif yeterliğe ilişkin kavramsal çerçevesinin genişletilmesi amacryla örgütsel ve bireysel çıktılarla bir arada incelendiğ̈i çalışmalar tasarlanabilir. Böylelikle kolektif yeterlik kavramı daha iyi anlaşılır ve okullarda bu birleşik güç algısından daha fazla yararlanılabilir.

Anahtar Kelimeler: Kolektif öğretmen yeterlĭgi, İş doyumu, Öğretmen 


\title{
Structural Equation Modeling on the Role of Teacher's Collective Efficacy in Teacher Job Satisfaction
}

\begin{abstract}
The study has aimed to reveal the relationship between collective teacher efficacy and teacher job satisfaction. In this study relational screening model has been used. The sample of this study consists of 235 teachers in 26 schools that were selected randomly with cluster sampling method from the schools at Hatay's Samandağ district in the 2018-2019 academic year. "Collective Teacher Efficacy Scale" and "Job Satisfaction Scale" were used to collect the data of this study. Teachers" perceptions on collective efficacy, instructional strategies and student discipline facets of collective efficacy, and job satisfaction are moderately high. According to structural equation modeling, collective teacher efficacy positively affects teacher job satisfaction. Also the instructional strategies and student discipline facets of collective teacher efficacy affect job satisfaction. Based on the study results, the collective efficacy perceptions of teachers have to be reinforced in order to promote their job satisfaction. Future studies can be designed to investigate the relationships between collective efficacy, and individual and organizational outputs to extend the conceptual framework regarding to collective efficacy. So collective efficacy concept can be understood better and the perception of combined power are more utilized in schools.
\end{abstract}

Keywords: Collective Teacher efficacy, Job satisfaction, Teacher 


\section{Giriş}

Bireyler; oluşabilecek problemleri önlemek, ortaya çıkan sorunları çözmek, şartlarını daha iyi hale getirmek, daha büyük başarılar elde etmek ve yaşam kalitelerini arttırmak için bir araya gelmekte, bilgi ve becerilerini paylaşmaktadırlar. Birbirlerinden destek alan ve yardımlaşan bireyler, zorlukları aşma konusunda daha azimli olmaktadırlar. Bireyler; bağlı olduğu grubun, belirli zorluklar karşısında yetkinliklerine güvenmekte ve bu durum psikolojik olarak kendilerini daha güçlü hissetmelerini sağlamaktadır. İçinde bulundukları grubun birleşik güçlerinin, öğrencilere öğretebilme ve sorunları aşabilme konularında yeterliğine inanan; diğer bir deyişle bağlı bulunduğu grubun kolektif yeterliğe sahip olduğunu algılayan öğretmenlerin, iş ortamlarından elde edecekleri memnuniyetin olumlu bir şekilde etkileneceği akla gelmektedir.

\section{Kolektif Yeterlik}

Öz yeterlik, kişinin amaçlarına ve kendisinden beklenen sonuçlara ulaşabileceğine olan inancıdır (Bandura, 1997). Öz yeterlik inancı; bireylerin belli zorluklarla mücadele etmede bilgi, beceri ve kapasitelerini tamamen kullanmalarını sağlayan psikolojik bir güçtür (Demir, 2018a; Hefferon ve Boniwell, 2011; Kreitner ve Kinichi, 2009; Luszczynska, Scholz ve Schwarzer, 2005). Bandura (1986); yeterlik inancinın sadece bireysel düzeyde değil, grup düzeyinde de olabileceğini ileri sürmektedir. İşte bu noktadan hareketle kolektif yeterlik algısı, öz yeterlik inancı esas alınarak ortaya atılan bir diğer önemli kavramdır (Duman, Göçen ve Duran, 2013; Goddard, Hoy ve Woolfolk-Hoy, 2000).

Bandura (1997, s.477); kolektif yeterliği, “belirli düzeylerde beceriler ortaya çıkarabilmek amacıyla gerekli eylem aşamalarını örgütleme ve yönetme yeteneklerine ilişkin, grubun paylaşılmış inancı" olarak tanımlamıştır. Maddux (2002) kolektif yeterliğin; bir grubun, istenen sonuçları elde edeceklerine ilişkin paylaşılmış inançları olduğunu belirtmektedir. Bu kapsamda değerlendirildiğinde öz yeterlik kavramı, daha çok kişisel yeterliğe yoğunlaşırken; kolektif yeterlik ise daha ziyade bütüncül düşünme ve işbirliği yapmaya vurgu yapmaktadır (Duman vd., 2013). Öğretmen öz yeterliği ile kolektif öğretmen yeterliği, kavramsal 
olarak farklı olup aralarında güçlü bir ilişki bulunmaktadır (Skaalvik ve Skaalvik, 2007). Nitekim, Bandura (1997); öz yeterlik ile kolektif yeterlik inancının, aynı kaynaklardan beslenen yapılar olduğunu belirtmektedir.

Kolektif öğretmen yeterliği; öğrencileri olumlu yönde etkilemek için eylem aşamaların düzenleyebilme ve yönetebilme yetkinliklerine sahip olduklarına ilişkin öğretmenlerin algıları toplamıdır (Goddard, Hoy ve Woolfolk-Hoy, 2004). Goddard vd. (2000, s.480) kolektif öğretmen yeterliğinin; okuldaki öğretmenlerin birleşik çabalarının, öğrenciler üzerinde olumlu bir etki oluşturabileceğine ilişkin algıları olduğunu ileri sürmektedir. Kurt (2012) ise kolektif yeterliği; öğretmenlerin, ortak kapasitelerine duydukları inanç, şeklinde tanımlamaktadır. Goddard vd. (2004) araştırmalarında, öğretmenlerin kolektif yeterliklerine ilişkin algılarının güçlü olmasının, öz yeterliklerini arttırdığını; kolektif yeterliklerine ilişkin algılarının zayıf olmasının ise öz yeterlik algıları üzerinde yıkıcı etkisinin olduğunu bulmuşlardır. Dolayısıyla öğretmenlerin birleşik kapasitelerine güvenmeleri, bireysel olarak kapasitelerine olan inançlarını etkilemektedir. Ayrıca Goddard vd. (2004) çalışmalarında; grubun yeterlik algısını arttırmanın, öğretmenlerin yaşantılarını değiştirebilecek yetkinliklere sahip olduklarına ilişkin kişisel algılarını güçlendirme yoluyla da mümkün olabileceğini ortaya çıkarmıştır. Diğer bir deyişle, öz yeterlik inancı güçlü olan öğretmenlerin kolektif yeterlik düzeyleri yüksek olabileceği gibi kolektif yeterlik inançları yüksek düzeyde olan öğretmenlerin öz yeterlik algıları yüksek olabilir. Bandura (1987); kolektif yeterlik ile öz yeterlik arasındaki bu durumu, karşılıklı nedensellik kavramı ile ifade etmiştir. Diğer bir anlatımla, kolektif öğretmen yeterliği ve öğretmen öz yeterliği karşılıklı ilişkili kavramlardır. Nitekim diğer araştırmalarda da (Goddard vd., 2000; Kurt, 2009; Skaalvik ve Skaalvik, 2007) kolektif yeterlik ile öz yeterlik algısının anlamlı ve pozitif ilişkili olduğu görülmektedir.

\section{İş Doyumu}

Kar amacı güden örgütlerde olduğu gibi eğitim örgütleri için de hayati öneme sahip kavramlardan biri iş doyumudur. İş doyumu, birçok araştırmada farklı bireysel ve örgütsel yapılarla incelenen, önemli bir anahtar değişkendir. Eren (2015) iş doyumu kavramının; bireyin meslektaşlarıyla çalışmaktan keyif alması ve üretmenin getirdiği mutluluk durumlarını 
kapsadığını belirtmektedir. Yeni ve Özler (2015) iş doyumunu; bireylerin işlerini ya da işlerindeki yaşantısını memnuniyet veren bir durum olarak algılamaları, şeklinde tanımlamaktadırlar. İş doyumu kavramının, üzerinde uzlaşılan bir tanımı bulunmamaktadır. İş doyumu yaşayan bireylerin, iş yerlerinde kendilerini psikolojik olarak iyi hissettikleri, bu kavrama ait tanımlardan anlaşılmaktadır.

\section{Araştırmanın Önemi ve Amacı}

Öğretmen öz yeterliğini konu alan çalışmaların fazla olmasına rağmen öz yeterlik kavramı ile aynı kaynaktan beslendiği tespit edilen kolektif öğretmen yeterliğine dair yapılan çalışmaların sınırlı sayıda olması dikkat çekicidir (Bandura, 1997; Skaalvik ve Skaalvik, 2007). Birleşik güç algısı oluşturan kolektif yeterliğin; önemli bazı kavramlarla ilişkisine dair çalışmaların yapılması, bu yapının daha iyi anlaşılması ve bu yapıdan eğitim örgütlerinde daha fazla yararlanılmasına imkan sunması bakımından gerekli görülmektedir. Kolektif öğretmen yeterliğinin, öğretmenlerin iş doyumları üzerindeki etkisine odaklanan bu çalışma, örgütsel hedeflere ulaşılmasını kolaylaştırmak amacıyla insan kaynakları yönetimine bazı açılardan katkı sağlaması düşünülerek tasarlanmıştır. Birincisi, kolektif yeterlik inancı ile iş doyumu ilişkisine yönelik güçlü bir kavramsal bir çerçeve sunulmaktadır. İkincisi, kolektif yeterliğin alt boyutlarından (öğretim stratejileri ve öğrenci disiplini) her birinin iş doyumu ile ilişkisine dair ayrı birer model geliştirilmiş ve sınanmıştır. Üçüncü olarak, kolektif yeterlik kavramı ile kavramsal çerçevenin genişletilmesi ve bu kavramdan eğitim örgütlerinde daha fazla yararlanılması düşünülmüştür. Bu çalışmada, kolektif öğretmen yeterliği ile iş doyumu arasındaki ilişkinin tespit edilmesi amaçlanmıştır. Belirtilen temel amaca ilişkin aşağıdaki hipotezler test edilmiştir:

H1: Kolektif öğretmen yeterliği, öğretmen iş doyumunu pozitif olarak etkilemektedir.

H2: Kolektif öğretmen yeterliğinin öğretim stratejileri boyutu, öğretmen iş doyumunu pozitif olarak etkilemektedir.

H3: Kolektif öğretmen yeterliğin öğrenci disiplini boyutu, öğretmen iş doyumunu pozitif olarak etkilemektedir. 


\section{Yöntem}

\section{Araştırmanın Modeli}

$\mathrm{Bu}$ araştırmada, değişkenler arasındaki ilişkilerin incelendiği ilişkisel tarama modeli (Büyüköztürk, Çakmak, Akgün, Karadeniz ve Demirel, 2012; Karasar, 2012) kullanılmıştır. Bu çalışmada; öğretmenlerin kolektif yeterlik ve kolektif yeterliğin boyutlarına ilişkin algıları ile iş doyum düzeyleri arasındaki ilişki tespit edilmektedir. Araştırmada; öğretmenlerin kolektif yeterlik ve kolektif yeterliğin alt boyutlarına ilişkin algıları, her biri ayrı bir modelde bağımsız değişken olarak ele alınmıştır. Geliştirilen modellerde, öğretmenlerin iş doyumlarına ilişkin algıları ise bağımlı değişken olarak kabul edilmiştir.

\section{Evren ve Örneklem}

Araştırmanın çalışma evrenini, 2018-2019 eğitim öğretim yılında Hatay ili Samandağ ilçesinde görev yapmakta olan öğretmenler oluşturmaktadır. Bu araştırmada, seçkisiz olarak belirlenen grupların örneklem için seçilmesi olarak ifade edilen oransız küme örnekleme yöntemi kullanılmıştır. Araştırmanın çalışma evreni olan Hatay’ın Samandă̆ ilçesinde bulunan 26 okul tesadüfî olarak seçilmiştir. Örnekleme alınan öğretmenlerin ( $n=235) \% 54$ 'ü erkek ( $n=127), \% 46$ 'sı kadınlardan $(n=108)$ oluşmaktadır. Katılımcıların \%79.1'i evli (n=49), \%20.9'u bekâr öğretmenler $(n=186)$ oluşturmaktadır. Bu katılımcıların en fazla bulundukları yaş aralığ1 \%42.6 ile 31-40 yaş aralığındaki öğretmenlerden $(n=100)$, en az bulundukları yaş aralığı ise \%26.4 ile 41 yaş ve üzeri öğretmenlerden $(\mathrm{n}=62)$ oluşmaktadir.

\section{Veri Toplama Araçları}

Veri toplama aracı olarak "Kişisel Bilgi Formu”, "Kolektif Öğretmen Yeterliği Ölçeği” ve "İş Doyumu Ölçeği”" kullanılmıştır. Beşli likert tipi ölçeklerin kullanıldı̆̆ı çalışmada ölçeklerin puanları, "1= Hiç katılmiyorum"; "2= Katılmiyorum"; " $3=$ Kismen kat1liyorum"; "4= 
Katılıyorum"; ve " $5=$ Tamamen katılıyorum" şeklinde değişiklik göstermektedir.

Kolektif Öğretmen Yeterlik ölçeği: Bu araştırmada; kolektif öğretmen yeterliğinin ölçümü için Tschannen-Moran ve Barr (2004) tarafından geliştirilen, Erdoğan ve Dönmez (2015) tarafından Türkçeye uyarlanan "Kolektif Öğretmen Yeterlik Ölçeği" kullanılmıştır. Ölçeğin orijinal formu 12 maddeden ve iki boyuttan oluşmaktadır. Kolektif Öğretmen Yeterlik Ölçeğinin Bartlett Küresellik Testinin sonucunun anlamlı ve KaiserMeyer-Olkin (KMO) katsayısının .915 olduğu tespit edilmiştir. Ölçekte maddelerin faktör yükleri .667 ile .852 arasında değiştiği görülmüştür. Öğretim stratejileri boyutun açıkladığ1 varyans yüzdesi 36.775, öğrenci disiplini boyutunun açıkladığı varyans yüzdesi 40.525 , ve bu iki boyutun açıkladığ1 toplam varyans yüzdesi 77.300 olarak bulunmuştur. Cronbach's Alpha Güvenirlik Katsayısı öğretim stratejileri boyutunda .838, öğrenci disiplini boyutunda .905 ve ölçeğin tamamında .927 olarak hesaplanmıştır. Ölçeğin orjinalindeki iki boyutlu faktör yapısı doğrulanmıştır $(\mathrm{X} 2=47.242, \mathrm{sd}=24, \mathrm{X} 2 / \mathrm{sd}=1.968, \mathrm{P}=0.003, \mathrm{RMSEA}=0.064$, GFI=.961, IFI=.986, TLI=.978, CFI=.986).

İş doyumu ölçeği, Griffin ve diğerleri (2010) tarafından geliştirilen ve Demir (2018c) tarafından Türkçeye uyarlanan "iş doyumu ölçeği (job satisfaction scale)" kullanılmıştır. Bartlett Küresellik Testi sonucu KaiserMeyer-Olkin (KMO) katsayısı 807 olarak hesaplanmıştır. Ölçek tek faktörlü bir yapıda olup bu tek faktör ölçme aracındaki toplam varyansın \%64.441'ini açılamaktadır. Faktör yükleri .526 ile .946 arasında değişmektedir. Güvenirlik analizi sonucu ise Cronbach's Alpha Güvenirlik Katsayısı .833 olarak bulunmuştur. Ölçeğin orjinalindeki tek boyutlu ve 5 maddelik faktör yapısı doğrulanmıştır $(\mathrm{X} 2=9.138$, sd=5, $\mathrm{X} 2 / \mathrm{sd}=1.828$, $\mathrm{P}=0.104, \mathrm{RMSEA}=0.059$, GFI=.985, $\mathrm{IFI}=.995, \mathrm{TLI}=.990, \mathrm{CFI}=.995)$.

\section{Veri Analizi}

Veriler; geçerlik ve güvenirlik açısından incelenmiş olup faktör analizi sonuçları ve Cronbach's Alpha güvenirlik katsayıları kullanılan ölçeklerin, geçerli ve güvenilir olduğunu ortaya koymuştur. Bu araştırmada veri analizi için güçlü bir istatistiki yöntem olan yapısal eşitlik 
modeli (YEM) (Meydan ve Şeşen, 2015) kullanılmıştır. YEM modelinin analizi için AMOS program kullanılmıştır. Doğrulayıc faktör analizi (DFA) aşamasında her bir ölçeğin faktör yapılarına ve bazı kriterler açısından iyi ya da kabul edilebilir uyum değerlerine sahip olup olmadıklarına bakılmıştır. X2/sd oranının iki ile üç arasında olması iyi bir uyumu, üç ile beş arasında olması ise kabul edilebilir bir uyumun varlığı olarak açıklanmaktadır; RMSEA değerinin 0.08 ile 0.05 arasında olması kabul edilebilir, 0.05 'in altında olması ise iyi bir uyum bulunduğunun göstergesi olarak kabul edilmektedir; TLI, CFI, ve IFI değerlerinin 0.90 ile 0.95 arasında olması kabul edilebilir bir uyum iyiliği değeri, 0.95 'ten büyük olması ise iyi bir uyum bulunduğunun göstergesi olduğu ifade edilmektedir (Byrne, 2010; Kline, 2011). GFI değerinin 0.85 ile 0.90 arasında olması kabul edilebilir bir uyum, 0.90'dan büyük olması ise iyi bir uyum bulunduğunun göstergesidir (Meydan ve Şeşen, 2015).

\section{Bulgular}

Öğretmenlerin araştırma kapsamında uygulanan ölçeklerdeki maddelere katılım düzeylerini gösteren aritmetik ortalama, standart sapma, standart hata değerleri ve korelasyon matrisi Tablo 1'de verilmektedir.

Table 1. Araştırma Kapsamında İncelenen Değişkenlerin Aritmetik Ortalama, Standart Sapma, Standart Hata ve Korelasyon Değerleri

\begin{tabular}{llllllll}
\hline Değişkenler & $\bar{X}$ & ss & $\begin{array}{l}\text { Std. } \\
\text { Hata }\end{array}$ & $\mathbf{1}$ & $\mathbf{2}$ & 3 & 4 \\
\hline Kolektif Yeterlik & 4.022 & .624 & .040 & 1 & & & \\
Öğretim Stratejileri & 4.023 & .628 & .041 & $.966^{* *}$ & 1 & & \\
Öğrenci Disiplini & 4.020 & .661 & .043 & $.969^{* *}$ & $.873^{* *}$ & 1 & \\
İş Doyumu & 4.181 & .712 & .046 & $.457^{* *}$ & $.438^{* *}$ & $.447^{* *}$ & 1 \\
${ }^{* *} p<.001$ & & & & & & &
\end{tabular}

Tablo 1'de görüldüğü üzere, kolektif öğretmen yeterliğine, kolektif öğretmen yeterliğinin alt boyutlarına (öğretim stratejileri ve öğrenci disiplini) ve iş doyumuna ilişkin öğretmen algıları kısmen yüksek yüzeydedir. Diğer bir ifadeyle "Katıllyorum:4" düzeyindedir. Korelasyon matrisindeki ilişkilere bakıldığında; kolektif öğretmen yeterliği ve kolektif 
öğretmen yeterliğinin alt boyutları ile iş doyumu arasındaki ilişkilerin pozitif anlamlı ve orta düzeyde olduğu görülmektedir.

Ölçüm modelindeki gizil (örtük) değişkenlerin tamamının istatistiki açıdan birbirleriyle pozitif ve anlamlı ilişkilere sahip olduğu Şekil 1'de görülmektedir.

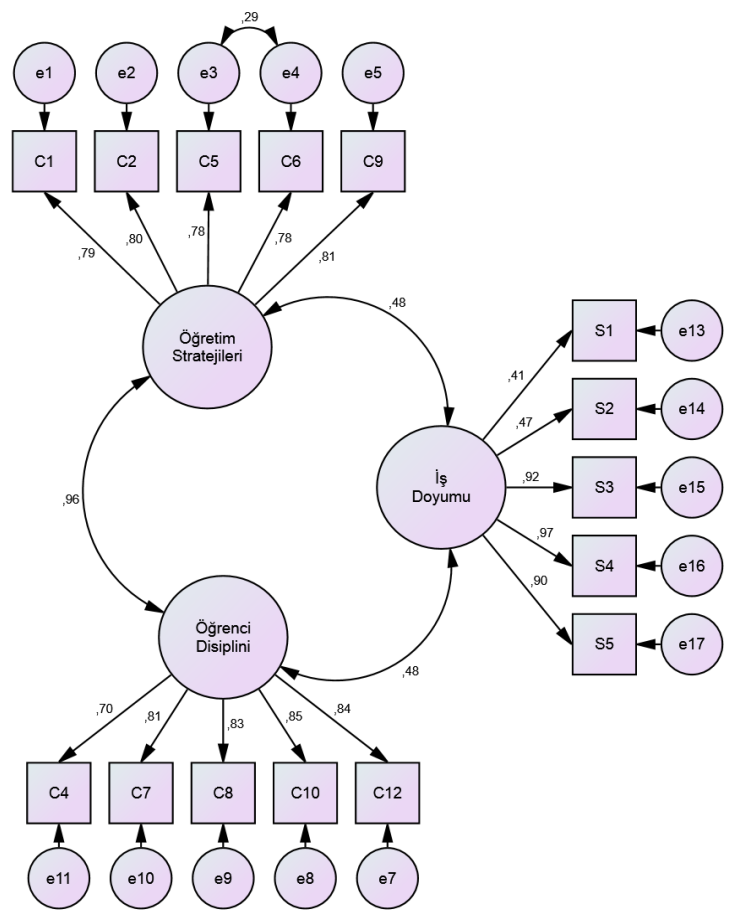

Şekil 1. Standardize Edilmiş Katsayılarla Ölçüm Modeli

Notlar: Uyum indisleri: $x 2=211.187, d f=86, x 2 / d f=2.456, p=.000, G F I=.896, I F I=.954, T L I=.943$, $C F I=.953$, RMSEA $=.079$

DFA çalışmada kullanılan tüm ölçeklere uygulandı. Modifikasyon indisleriyle uyumlu olarak 2 madde modelden çıkarıldı ve modele 1 kovaryans eklendi. Hata varyanslarının çok yüksek olması ve ki kare değerini oldukça fazla düzeyde yükseltmelerinden dolayı sırasıyla C3 ve C11 maddeleri modelden silindi. Hata kovaryansları, C5 ile C6 arasina bu maddelerdeki hataların birbiriyle ilişkili olmasından dolayı eklendi. Ölçüm modeli, ölçeklerin verilerle iyi düzeyde uyum sağladığını 
göstermektedir $(\mathrm{x} 2=211.187, \mathrm{df}=86, \mathrm{x} 2 / \mathrm{df}=2.456, \mathrm{p}=.000, \mathrm{GFI}=.896, \mathrm{IFI}=$ $.954, \mathrm{TLI}=.943, \mathrm{CFI}=.953, \mathrm{RMSEA}=.079$ ).

Kolektif öğretmen yeterliğinin, öğretmen iş doyumu üzerindeki etkisine ilişkin yapısal model Şekil 2'de görülmektedir.

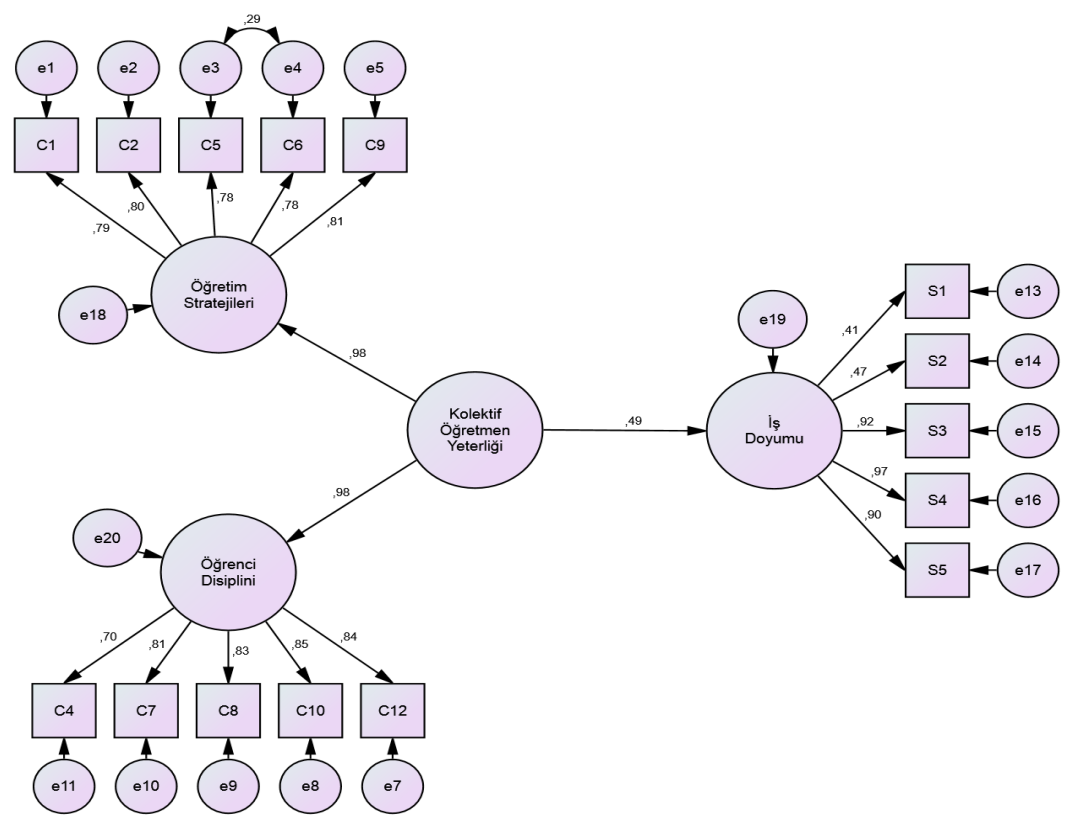

Şekil 2. Standardize Edilmiş Katsayılarla Kolektif Öğretmen Yeterliğinin, Öğretmen İş Doyumunu Etkilemesine İlişkin Yapısal Model

Notlar: Uyum indisleri: $x 2=211.487, d f=86, x 2 / d f=2.456, p=.000, G F I=.896, I F I=.954, T L I=.943$, $C F I=.953$, RMSEA $=.079$

En iyi uyum indekslerini üreten yapısal modele göre; kolektif öğretmen yeterliği, öğretmenlerin iş doyum düzeylerini pozitif olarak etkilemektedir $(\beta=.49, \mathrm{p}<0.01)$. Kolektif öğretmen yeterlik algısındaki bir birimlik artış, .49 birimlik öğretmen iş doyumu artışını sağlamaktadır. Kolektif öğretmen yeterliğine ilişkin olumlu algılar arttıkça, öğretmenlerin iş doyumları da artmaktadır. 
Kolektif öğretmen yeterliğinin öğretim stratejileri alt boyutunun, öğretmen iş doyumu üzerindeki etkisine yönelik yapısal model Şekil 3'te verilmektedir.

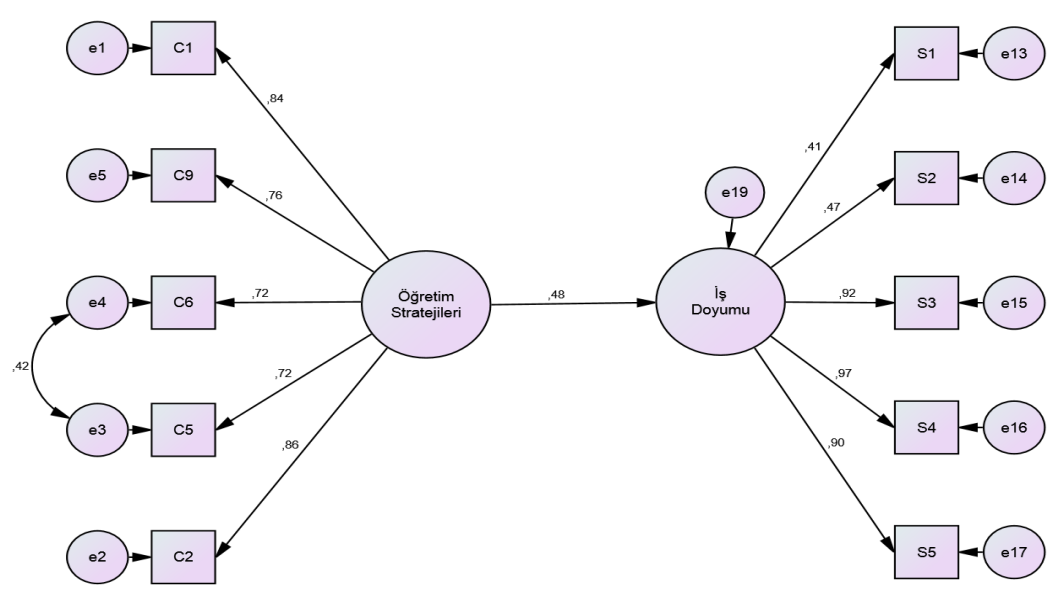

Şekil 3. Standardize Edilmiş Katsayılarla Öğretim Stratejileri Alt Boyutunun İş Doyumuna Etkisine Yönelik Yapisal Model

Notlar: Uyum indisleri: $x 2=63.636, d f=33, x 2 / d f=1.928, p=.001, G F I=.949, I F I=.981, T L I=.973, C F I$ $=.980$, RMSEA $=.063$

Kolektif öğretmen yeterliğinin öğretim stratejileri alt boyutu, öğretmen iş doyumunu pozitif olarak etkilemektedir $(\beta=.48, \mathrm{p}<0.01)$. Bir birimlik öğretim stratejilerine ilişkin öğretmen algısındaki artış, .48 birimlik öğretmen iş doyumu artışını sağlamaktadır. Öğretim stratejilerine ilişkin olumlu algılar arttıkça, iş doyumu da artmaktadır.

Kolektif öğretmen yeterliğinin öğrenci disiplini alt boyutunun, öğretmen iş doyumu üzerindeki etkisine dair yapısal model Şekil $4^{\prime}$ te sunulmaktadir. 


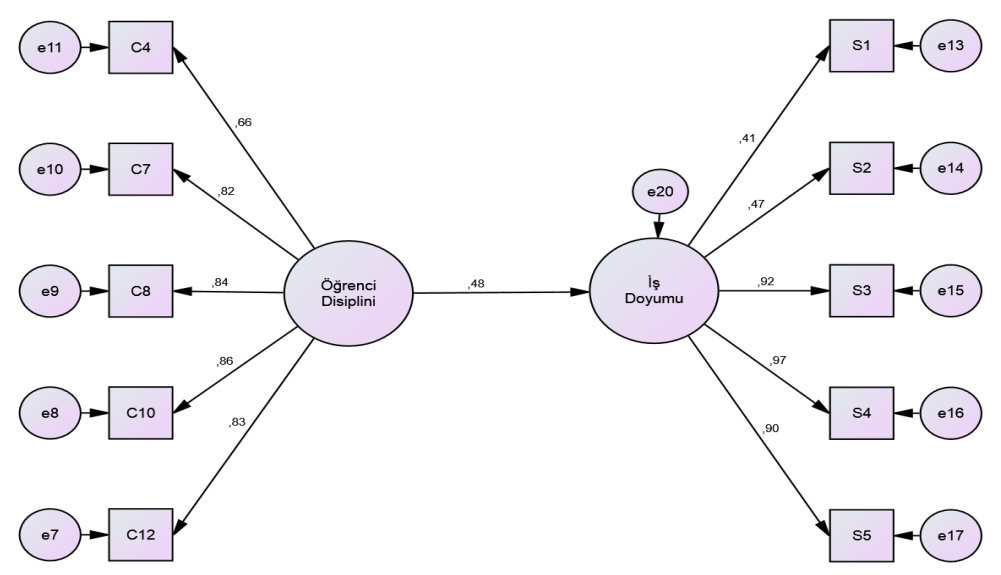

Şekil 4. Standardize Edilmiş Katsayılarla Öğrenci Disiplini Alt Boyutunun İş Doyumuna Etkisine Dair Yapisal Model

Notlar: Uyum indisleri: $x 2=70.860, d f=34, x 2 / d f=2.084, p=.00, G F I=.947$, IFI $=.977$, TLI $=.970, C F I=.977$, RMSEA $=.068$

Kolektif öğretmen yeterliğinin öğrenci disiplini alt boyutu, öğretmen iş doyumunu pozitif olarak etkilemektedir $(\beta=.47, \mathrm{p}<0.01)$. Her bir birimlik öğrenci disiplinine ilişkin öğretmen algısındaki artış, .47 birimlik iş doyumu artışına katkı yapmaktadır. Öğrenci disiplinine ilişkin olumlu algılar arttıkça, öğretmenlerin iş doyumlarının da arttığı görülmektedir.

\section{Tartışma, Sonuç ve Öneriler}

Bu çalışmada; öğretmenlerin kolektif yeterliklerine ilişkin olumlu algıları arttıkça, iş doyumlarının da arttığı bulunmuştur. Böylelikle H1 hipotezi doğrulanmıştır. Kolektif öğretmen yeterliğinin; öğretim stratejileri (H1) ve öğrenci disiplini (H2) alt boyutlarının, iş doyumunu olumlu etkilediği tespit edilmiştir. Dolayısıyla test edilen $\mathrm{H} 2$ ve $\mathrm{H} 3$ hipotezleri de 
doğrulanmıştır. Araştırmada, test edilen hipotezlerin tamamının doğrulandı̆̆ görülmüştür.

Goddard ve diğerleri (2004) araştırmalarında; kolektif yeterlik algisının, örgütsel hedeflere ulaşılmasında önemli bir etken olduğunu ortaya çıarmışlardır. Araştırmalarında kolektif yeterliğin; öğretmenlerin yaşantılarını etkileme yoluyla öğrenci başarısı, öğretmen bağlılığı ve iş doyumu gibi tutumlar üzerinde olumlu etkide bulunduğunu ortaya çıkarmışlardır. Benzer şekilde bu çalışmada da kolektif öğretmen yeterliğinin, öğretmen iş doyumunu arttırdığı bulunmuştur. Okulundaki meslektaşlarının; sınıf yönetimi ve öğretim stratejilerinde iyi olduklarını düşünen öğretmenler, onlarla birlikte bütün zorlukların üstesinden geleceklerine ve başarılı olacaklarına inanırlar. Onlarda oluşan bu inanç, psikolojik yapılarına olumlu bir şekilde doğrudan tesir eder. Nitekim Goddard ve arkadaşları (2004); bireylerin beceri ve yetkinliklerine ilişkin inançlarının, mevcut durumlarını yansıtmasa bile grupların ve bireylerin sergiledikleri performans üzerinde, çoğunlukla gerçekle uyuşmayan bu algılamaların etkili olduğunu ileri sürmektedirler.

Öğretmenlerin; okul olarak bir şeyler üretebileceklerini ve örgütsel hedeflere ulaşabilecek yeterliğe sahip olduklarını düşünmeleri, öz yeterlik düzeylerini arttırır (Goddard vd., 2000, 2004; Kurt, 2009; Skaalvik ve Skaalvik, 2007). Öz yeterlik inançlarının ise iş doyumu ile ilişkili olduğu araştırmalarda kanıtlanmıştır (Demir, 2018b). Dolayısıyla kolektif yeterliğin, bireysel yetkinlikleri arttırma yoluyla da öğretmenlerin memnuniyetlerini arttıracağı akla gelmektedir.

Bu çalışmada kolektif yeterliğin; öğretim stratejileri ve öğrenci disiplini alt boyutlarının, öğretmenlerin iş doyumunu arttırdı ğı bulunmuştur. Okullar, sosyal kurumlar olduğundan belirli sorunların aşılması ve iyileştirmelerin yapılabilmesi için birleşik bir güce ihtiyaç duyulmaktadır. Bu doğrultuda, öğretim ve benzeri konularda güçlü olduklarını algılayan öğretmenler; işlerini iyi yaptıklarını düşünmekte ve kendilerini mutlu hissetmektedirler. Önceki araştırmalar (Durham, Knight ve Locke, 1997; Lee ve Fahr, 2004; Myers, Feltz ve Short, 2004; Myers, Paiement ve Feltz, 2007); kolektif yeterlik algısı ile sergilenen performansın, dikkate değer bir ilişki içerisinde olduğunu ortaya koymaktadır. Bu yetkinlik alg1sı, öğretmenlerin mevcut durumlarını güçlendirmektedir. Nitekim Bandura 
(1997); grupların ya da örgütlerin güçlerinin, bu grup ya da örgütteki insanların birleşik güçlerinden kaynaklandığını ileri sürmektedir. Böylelikle öğretmenler, birlikte çalıştıkları meslektaşlarıyla okuldaki görevlerin daha sağlıklı yürüyeceğine inanmaktadırlar. Diğer bir deyişle birey; okuldaki meslektaşlarıyla yapacağı işbirliğinin, olumlu sonuçlar doğuracağına güvenmektedir. Bu gibi olumlu hisler, öğretmenlerin işlerinde memnuniyet algılamalarını sağlamaktadır.

Bu araştırmada; kolektif yeterlik kavramının, öz yeterlik kavramı esas alınarak ortaya atılmasından dolayı öz yeterlikle arasındaki kavramsal farklılıklar ve aralarındaki ilişki incelenmiştir. Daha sonra kolektif yeterliğin, öz yeterlikle ilişkisi ortaya konulmuştur. Son olarak ise kolektif yeterliğin; öğretim stratejileri ile öğrenci disiplini alt boyutlarının, iş doyumuna etkisi açığa çıkarılmıştır.

İleriki araştırmalarda, eğitim örgütleri açısından oldukça önemli görülen kolektif yeterliğe ilginin artması gerekmektedir. Kolektif yeterliğin, kavramsal çerçevesinin genişletilmesi için örgütsel ve bireysel çıtılarla bir arada incelendiği çalışmalar tasarlanabilir. Böylelikle kolektif yeterlik kavramı daha iyi anlaşılır ve okullarda bu birleşik güç algısından daha fazla yararlanılabilir. 


\title{
EXTENDED ABSTRACT
}

\section{Structural Equation Modeling on the Role of Teacher's Collective Efficacy in Teacher Job Satisfaction}

\author{
Selçuk Demir
}

\section{Ministry of National Education}

People put together and share their knowledges, skills and talents in order to solve possible problems, live in better conditions and to be accomplished. These individuals supporting on and helping each other become more determined to cope with all kinds of challenges faced at corporate. Because these individuals count on the competence of the group in that they are. This state makes individuals feel psychologically more powerful. Combined power positively influences teachers' emotions and manners at work. Teachers in these groups who have competences believe that they are capable of doing best, so they are satisfied with working together at these corporates.

Despite the majority of the investigations on self-efficacy, there are restricted studies regarding collective efficacy. Whereas collective efficacy has been propounded based upon self-efficacy concept. These structures are strongly related to each other. Filling this gap, this study has envisioned to present major contributions to the human resource management by facilitating to reach the organizational objectives. Firstly the current study produces an integrated model revealing the relationship between collective teacher efficacy and job satisfaction. Secondly the models are proposed and tested regarding the relationships between sub-dimensions of collective teacher efficacy (instructional strategies and student discipline) and job satisfaction. Lastly the conceptual framework related to collective teacher efficacy are extended to be taken advantages of this psychological power.

This research has aimed to point out the relationships between collective efficacy and its dimensions with the teacher's job satisfaction. In line with the purpose, this paper focuses on testing the following hypothesises: 
H1: Collective teacher efficacy has a positive impact on teacher's job satisfaction.

$\mathrm{H} 2$ : Instructional strategies sub-dimension of collective teacher efficacy has a positive impact on teacher's job satisfaction.

H3: Student discipline sub-dimension of collective teacher efficacy has a positive impact on teacher's job satisfaction.

\section{Method}

This study was designed by a relational screening model that explains the relationships between two or more variables and gives an idea in terms of the probability of cause and effect relation between variables (Büyüköztürk et al., 2012; Karasar, 2012). While each of collective teacher efficacy and its two dimensions were taken as independent variables in the separate structural models, job satisfaction was taken as a dependent variable.

The research sample consists of 235 teachers in 26 schools affiliated to the Ministry of National Education in Hatay's Samandağ district in the 2018-2019 academic year. According to Field (2009) this sample size was enough at $95 \%$ confidence interval for this population of study.

Data of this study were obtained by five-point Likert-type scales. The points of the scale are differentiated as $1=I$ don't agree at all; $2=I$ don't agree; 3= I agree partially; 4= I agree; and 5= I totally agree. Two different scales were used in this study as follows. Collective teacher efficacy scale that was developed by Tschannen-Moran ve Barr (2004) and adapted to Turkish by Erdoğan ve Dönmez (2015). This scale has two sub-dimensions: Intrustional strategies and student discipline. In the stage of confirmatory factor analysis, the orginal two-dimensioned factorial structure has been confirmed $(\mathrm{X} 2=47.242, \mathrm{df}=24, \mathrm{X} 2 / \mathrm{df}=1.968, \mathrm{P}=0.003$, RMSEA=0.064, GFI=.961, IFI=.986, TLI=.978, CFI=.986). Cronbach's Alpha for instructional sub-dimension was .838, student discipline sub-dimension was .905 and overall scale was 0.927 .

Job satisfaction scale was developed by Griffin et al. (2010) and adapted to Turkish by Demir (2018c). The orginal single-dimensioned factorial 
structure has been confirmed by confirmatory factor analysis $(X 2=9.138$, $\mathrm{df}=5, \mathrm{X} 2 / \mathrm{df}=1.828, \mathrm{P}=0.104$, RMSEA=0.059, GFI=.985, IFI=.995, TLI=.990, CFI $=.995)$. Cronbach's Alpha of the scale was 0.833 .

\section{Results}

Teachers' perceptions on collective efficacy, instructional strategies and student discipline facets of collective efficacy, and job satisfaction are moderately high. Measurement model shows study variables are positively correlated with each other. Structural equation modeling has found out that collective teacher efficacy positively affects teacher job satisfaction. Also the instructional strategies and student discipline facets of collective teacher efficacy affect teachers' job satisfaction. Collective teacher efficacy is a combined power that fosters teachers' positive ideas regarding the satisfaction with their job. This current study has extended to the conceptual framework of collective teacher efficacy to benefit from this psychological power.

Future researches have to be designed to be utilized this combined power that points out the relationships between collective teacher efficacy and performance variables. School administrators are recommended to help combined power belief constitute. Thus, human resource can be managed well to be achieved organizational and individual goals. Teachers believe in having competences of being successful while they are working together at school.

\section{Kaynakça / References}

Bandura, A. (1986). Social foundations of thought and action: A social cognitive theory. Englewood Cliffs, NJ: Prentice-Hall.

Bandura, A. (1997). Self-efficacy: The exercise of control. New York: W. H. Freeman and Company.

Büyüköztürk, Ş., Çakmak, E.K., Akgün, Ö.E., Karadeniz, Ş. V. ve Demirel, F. (2012). Bilimsel araştırma yöntemleri. Ankara: PegemA.

Byrne, B. M. (2010). Structural equation modeling with AMOS. New York: Routledge. 
Demir, S. (2018a). Okul yöneticilerinin motivasyonel dili ile öğretmen öz yeterliği arasındaki ilişki üzerine bir çalışma. Anemon Muş Alparslan Universitesi Sosyal Bilimler Dergisi, 6(2), 177-183. DOI: 10.18506/anemon.384848

Demir, S. (2018b, Mayıs). Öz yeterliğin iş doyumu, örgütsel bağlllık, motivasyon ve işe sarginlıktaki rolü, 6. Uluslarası Eğitim Araştırmaları Kongresi, 02-05 Mayıs 2018, Antalya.

Demir, S. (2018c). Structural capital's contribution to teacher's job satisfaction: The mediating role of organizational commitment. International Journal of Educational Methodology, 4(4), 195-203. doi: 10.12973/ijem.4.4.195

Duman, B., Göçen, G. ve Duran, V. (2013). İlköğretim Öğretmenlerinin Kolektif Yeterlik Düzeylerinin Çeşitli Değişkenler Açısından İncelenmesi. Hacettepe Üniversitesi Ĕ̆itim Fakültesi Dergisi, Özel sayı (1), 144-155.

Durham, C. C., Knight, D. ve Locke, E. A. (1997). Effects of leader role, team-set goal difficulty, efficacy, and tactics on team effectiveness. Organizational Behavior and Human Performance, 72(2), 203-231.

Erdoğan, U. ve Dönmez, B. (2015). Kolektif öğretmen yeterliği ölçeğinin Türkçeye uyarlanması: Geçerlik ve güvenirlik çalışması. Kuram ve Uygulamada Eğitim Yönetimi, 21 (3), 345-366. doi: 10.14527/kuey.2015.013.

Eren, E. (2015). Örgütsel davranış ve yönetim psikolojisi. Ankara: Beta Yayıncilik.

Field, A. (2009). Discovering Statistics using SPSS. Dubai: Oriental Press.

Goddard, R. D., Hoy, W. K. ve Woolfolk Hoy, A. (2000). Collective teacher efficacy: Its meaning, measure, and impact on student achievement. American Educational Research Journal, 37 (2), 479-507.

Goddard, R. D., Hoy, W. K. ve Woolfolk Hoy, A. (2004). Collective efficacy: Theoretical development, empirical evidence, and future directions. Educational Researcher, 33(3) 3-13.

Griffin, M.L., Hogan, N.L., Lambert, E.G., Tucker-Gail, K.A. ve Baker, D.N. (2010). Job involvement, job stress, job satisfaction, and organizational commitment and the burnout of correctional staff. Criminal Justice and Behavior, 37, 239-255. 
Hefferon, K. ve Boniwell, I. (2011). Positive Psychology: Theory, Research and Applications. New York: Mc Graw-Hill Open International Publishing Ltd.

Karasar, N. (2012). Bilimsel araştırma yöntemi. Ankara: Nobel.

Kline, R.B. (2011). Principles and practice of structural equation modeling. New York: The Guilford Press.

Kreitner, R. ve Kinichi, A. (2009). Organizational behaviour (9th ed.). New York: Mc Graw-Hill International Edition.

Kurt, T. (2012). Öğretmenlerin öz yeterlik ve kolektif yeterlik algıları. Türk Eğitim Bilimleri Dergisi, 10(2), 195-227.

Kurt, T. (2009). Okul müdürlerinin dönüşümcü ve eylemci liderlik stilleri ile ögrretmenlerin kolektif yeterliği ve öz yeterliği arasındaki ilişkilerin incelenmesi. Yayımlanmamış doktora tezi, Gazi Üniversitesi, Ankara.

Lee, C. ve Fahr, J. (2004). Joint effects of group efficacy and gender diversity on group cohesion and performance. Applied Psychology: An International Review, 53(1), 136-154.

Lunenburg, F.C. ve Ornstein, A.C. (2012). Educational administration: concepts and practices. Boston: Wadsworth Cengage Learning Publishing, Sixth Edition.

Luszczynska, A., Scholz, U. ve Schwarzer, R. (2005). The general self-efficacy scale: Multicultural validation studies. The journal of Psychology, 139(5), 439-457.

Maddux, J. (2002). Self-efficacy: The power of believing you can. In C.R. Synder and S.J. Lopez (eds), Handbook of positive psychology (pp. 277-287). New York: Oxford University Press.

Meydan, C.H. ve Şeşen, H. (2015). Yapısal eşittik modellemesi, Amos uygulamaları. Ankara: Detay Yayincilik.

Myers, N. D., Feltz, D. L. ve Short, S. E. (2004). Collective efficacy and team performance: A longitudinal study of collegiate football teams. Group Dynamics: Theory, Research, and Practice, 8(2), 126-138.

Myers, N. D., Paiement, C. A. ve Feltz, D. L. (2007). Regressing team performance on collective efficacy: Considerations of temporal proximity and concordance. Measurement in Physical Education and Exercise Science, 11(1), 1-24. 
Skaalvik, E. M. ve Skaalvik, S. (2007). Dimensions of teacher self-efficacy and relations with strain factors, perceived collective teacher efficacy, and teacher burnout. Journal of Educational Psychology, 99 (3), 611-625.

Skaalvik, E.M. ve Skaalvik, S. (2010). Teacher self-efficacy and teacher burnout: A study of relations. Teaching and Teacher Education, 26, 1059-1069.

Tschannen-Moran, M. ve Barr, M. (2004). Fostering student learning: The relationship of collective teacher efficacy and student achievement. Leadership and Policy in Schools, 3 (3), 189-209.

Yeni, Z. ve Özler, N.D.E. (2015). Duygusal emek. N.D.E. Özler (Ed.)., Örgütsel davranışta güncel konular içinde (ss. 329-362). Bursa: Ekin Yayınevi.

\section{Kaynakça Bilgisi / Citation Information}

Demir, S. (2019). Kolektif öğretmen yeterliğinin öğretmen iş doyumundaki rolü üzerine yapısal eşitlik modellemesi. OPUS-Uluslararası Toplum Araştırmaları Dergisi , 10(17), 444-463. DOI: 10.26466/ opus.496333 